\title{
El sistema de compatibilidades entre el trabajo y la jubilación en los ordenamientos previsionales nacional y de la provincia de Buenos Aires
}

\section{POR ADOLFO NICOLÁS BALBÍN $(*)$}

\begin{abstract}
Sumario: I. Introducción.- II. La contratación laboral en relación con el tiempo, y las incidencias jurídicas de dicho factor.- III. La jubilación como causal ordinaria de extinción del contrato de trabajo. El sistema nacional y la reforma de la ley 27.426.- IV. Recaudos para el acceso a la jubilación ordinaria en la provincia de Buenos Aires.- V. El mecanismo de compatibilidades entre el trabajo y la jubilación dentro del ordenamiento nacional. La regla.- VI. Las incompatibilidades reguladas como excepción en el sistema nacional.- VII. Las compatibilidades previsionales en la provincia de Buenos Aires. Algunas comparaciones con el régimen nacional.- VIII. Conclusiones.- IX. Bibliografía.
\end{abstract}

Resumen: en este trabajo se analiza el sistema de compatibilidades entre los roles de trabajador en relación de dependencia y jubilado y, por derivación, la posibilidad que una persona tiene de acumular en un mismo tiempo, el salario con el goce del haber previsional. Para ese estudio, se parte del sistema previsional nacional regulado en la ley 24.241 y su paralelo de la provincia de Buenos Aires, decreto ley 9650/80. El objetivo del trabajo es lograr comprender las características principales de cada uno de ellos y, a la vez, construir posibles vinculaciones entre ambos. Si bien este artículo apunta más que nada al estudio de institutos de la seguridad social, conscientes de la interrelación que media entre esa rama jurídica y el derecho del trabajo, al inicio de la investigación se invierte la prevalencia y se comienza por estudiar las tipologías contractuales y la jubilación como su forma de extinción ordinaria.

Palabras claves: compatibilidad - trabajo - jubilación

The system of compatibilities between labor and retirement in the national previsional systems and the province of Buenos Aires

(*) Abogado (UNLP). Especialista en Derecho Social (UNLP). Prof. Adjunto de Derecho Social, Facultad de Ciencias Jurídicas y Sociales, Universidad Nacional de La Plata (UNLP). 
Abstract: this paper analyzes the system of compatibilities between the roles of worker in relation of dependence and retiree and, by derivation, the possibility that a person has to accumulate in a same time, the salary with the enjoyment of the pension provision. For this study, part of the national pension system regulated in Law 24.241 and its parallel of the Province of Buenos Aires, Decree Law 9650/80. The objective of the work is to understand the main characteristics of each one of them and, at the same time, to build possible links between both. Although this article aims more than anything at the study of social security institutes, aware of the interrelation that mediates between that legal branch and labor law, at the beginning of the investigation the prevalence is reversed and the contractual typologies are studied and retirement as their ordinary form of extinction.

Keywords: compatibility - work - retirement

\section{Introducción}

Existe una profunda vinculación entre el derecho del trabajo y el de la seguridad social que aconseja formalizar debates de manera conjunta para combinar los elementos propios de cada una de esas disciplinas.

Uno de esos debates se afinca en la posibilidad de que una misma persona pueda acumular los roles de trabajador en relación de dependencia con el de jubilado, y gozar de manera paralela, como conclusión de ello, de la remuneración fruto de la puesta a disposición de la energía corporal a favor de un tercero, así como también de la jubilación como débito de la comunidad por los servicios que se han cumplido durante la vida activa.

Y para su entendimiento, necesariamente se recurren, con mayor o menor profundidad (dependiendo del caso) a institutos que conforman la columna vertebral de cada una de las disciplinas jurídicas antes identificadas.

Como se escribe en el título de este artículo, el punto de partida aquí es el análisis del sistema de compatibilidades entre los roles de trabajador dependiente y jubilado, dentro del ordenamiento previsional nacional estructurado en el marco de la ley 24.241 y el de la Provincia de Buenos Aires vertebrado a partir del decreto ley $9650 / 80$.

Para ello, tomando en cuenta la interrelación existente entre las dos ramas agrupadas dentro del derecho social, se parte del estudio de ciertos componentes clave que encontramos dentro del derecho del trabajo. Ampliando, se estudian someramente las diversas formas legales con que se pueden vincular los trabajadores con los empleadores, y se puntualiza dicha pesquisa en las arenas donde campean algunos elementos del contrato por tiempo indeterminado. 
Se combinan esos componentes con el factor tiempo, mencionándose a la jubilación como el modo ordinario de extinción del vínculo jurídico laboral.

Desde allí, sin olvidarnos del dato laboral, se le otorga prioridad al campo de la seguridad social y se comienzan a analizar los sistemas nacional y provincial antes identificados, en derredor del punto de contacto seleccionado, es decir, la posibilidad de acumulación de los derechos a la remuneración y a la jubilación.

El estudio sobre el que se labora en este artículo de doctrina no se afinca solamente en el análisis de la ley positiva, sino que, partiendo de la misma, se la complementa en todo momento con algunos parámetros provenientes de la jurisprudencia, ciertas apreciaciones de la doctrina de otros autores y también con la opinión del que escribe estas páginas.

El método comparativo que se ha seleccionado para analizar el tema central de la compatibilidad previsional, tuvo por fin no solamente estudiar las características más sobresalientes de los regímenes previsionales más importantes a nivel nacional y provincial, sino poder comprender, con base en el confronte normativo, el sentido de cada uno así como también pensar en la posibilidad futura de proponer ciertas reformas que los mejoren, siempre con miras a lograr la más óptima materialización de la justicia en los casos concretos que es, en definitiva, el valor instrumental de todos los cuerpos normativos.

Esa raigambre tutelar del derecho social afinca en las dos ramas autónomas que anidan académica e históricamente en su seno. Y, desde el estudio de sus respectivas competencias, se ha hecho uso de algunos de sus institutos más representativos con miras a la ampliación de su sentido y comprensión.

\section{La contratación laboral en relación con el tiempo y las incidencias jurídicas de dicho factor}

El carácter instrumental del contrato de trabajo —o relación jurídica laboralse traduce en lo cotidiano de nuestra existencia política, en la creación de un conjunto de mecanismos legales que permiten que dos o más personas puedan vincularse a los fines de satisfacer intereses comúnmente diferentes, aunque no del todo contrapuestos, traducido ello en el nacimiento de dos acreencias que, desde un punto de vista económico, dan lugar al precio de los factores de la producción trabajo y capital, como son el salario y el interés o utilidades empresariales, respectivamente.

De aquellos, uno tendrá origen en un aspecto puramente personal, como derivación del cuerpo de quien, empujado por una situación de necesidad, aporta toda o parte destacable de su persona; mientras el otro, sin desmerecimiento 
alguno en las páginas que corren, se materializa como la ganancia derivada de la aportación de un capital ya no humano ni personal (al menos no directamente), sino económico.

La persona que presta servicios laborales y que aporta, por ende, toda o parte esencial de su energía corporal, recibe a cambio un salario como fruto de esa participación relacional. A su turno, quien se obliga a entregar un capital económico, dirigiendo y organizando la empresa con poderes limitados en algún aspecto y exorbitantes en otros, recibe la ganancia derivada de la venta de los productos fabricados o de los servicios brindados.

Como se ve, son las descriptas, motivaciones concurrentes dentro de un negocio que en apariencia es celebrado por personas totalmente libres de contratar. Ello sin perjuicio de que, el derecho del trabajo, reaccionando frente a esa realidad conflictiva derivada del desigual poder negocial en que se encuentran quienes ponen su fuerza de trabajo a disposición de otro, y quienes se apropian de la misma a cambio de un precio valorable en dinero, trate de canalizar el mismo con base en un conjunto de normativas organizadas en una serie de institutos regulatorios que permitan - al menos en parte- equilibrar tal balanza jurídica personal.

Unos de esos conjuntos regulatorios resultan ser aquellos que tipifican los diferentes tipos contractuales a los que pueden recurrir los trabajadores y los empleadores a fines de enlazar sus voluntades concurrentes dentro de la relación laboral.

En todos aquellos tipos, podremos ver que el factor tiempo determina el nacimiento de derechos solamente en parte similares, y en esencia naturalmente distanciados.

Con razón ha dicho Fernández Madrid que "un mínimo de tiempo es necesario para que se configure un contrato de trabajo" (2007, p. 851), lo que nos da la pauta de que la relación laboral no es por esencia atemporal, sino todo lo contrario. Existe en el hoy y en el ahora, aunque también con incidencias en el pasado - derivado ello de los derechos adquiridos a través de la antigüedad, o sucesos pasados que puedan ser el origen de futuras reclamaciones- y en el futuro - traducido ello en el carácter previsional de los actuales comportamientos desplegados por quienes negocian, y que dan lugar al devengamiento de derechos como los indemnizatorios, o bien la jubilación-.

Sin perjuicio de la trascendente incidencia del factor tiempo dentro del contrato de trabajo, es dable señalar que el mismo puede adquirir negociablemente diferentes facetas o amplitudes, dándose lugar al tema de las tipologías contractuales o bien a los diversos matices modales que pueden adquirir los negocios celebrados entre un trabajador y un empleador. 
EL SISTEMA DE COMPATIBILIDADES ENTRE EL TRABAJO Y LA JUBILACIÓN EN LOS ORDENAMIENTOS PREVISIONALES NACIONAL Y DE LA PROVINCIA DE BUENOS AIRES

Como regla, el ordenamiento laboral individual madre dentro de nuestro país (Ley de Contrato de Trabajo No 20.744(1), que también individualizaremos como LCT) con lenguaje imperativo, determina en su artículo 90 que el contrato de trabajo se deberá entender celebrado por tiempo indeterminado, refiriendo, con carácter secundario, a ciertas situaciones excepcionales que podrían apartarnos de la regla antes enunciada, siempre que se cumplimenten (de forma acumulativa) las dos condiciones prescriptas por el legislador en los incisos a) y b) del artículo mencionado (2).

Eso da lugar a las llamadas modalidades del contrato de trabajo - que podríamos denominar también como tipologías excepcionales, dado el carácter antes enunciado- las que establecen relaciones diversas con relación al tiempo del que, como factor, ya hicimos referencia.

De esa forma nos encontramos con los contratos por tiempo indeterminado de prestaciones discontinuas - vinculación de temporada- cualificados por la existencia de prestaciones recíprocas y principales (deberes de cumplimiento) desarrollados en determinada época del año en tanto se cumpla un ciclo de producción y/o explotación, y otras complementarias (deberes de conducta), que se deben materializar a lo largo de todo el año; y los de tiempo determinado, que a su vez pueden ser de tiempo cierto - plazo fijo, determinantes de contratos con duración limitada (hasta cinco años) conocida desde el inicio por ambas partes-, o bien incierto - relación eventual, que da lugar a vinculaciones cuyo tiempo final concreto es desconocido por ambas partes, a los contratos de interinado, o bien a aquellos cuya duración única culmina con la realización de una obra o la ejecución de un servicio-(3).

Amén de las tipologías anteriormente enunciadas, en el derecho del trabajo, si bien existen diversas formas a partir de las cuales las partes pueden ensamblar sus voluntades dentro del núcleo obligacional, solamente a una de ellas el legislador le ha dado prioridad. Se trata del contrato por tiempo indeterminado genérico que, aún sin derecho a la estabilidad, coloca en cabeza del trabajador o de la trabajadora la expectativa de permanecer dentro del negocio laboral hasta que se materialicen las situaciones límites que, con carácter de ordinario o bien de relativa consideración, determinen la culminación del vínculo oportunamente celebrado.

(1) B.O. 27/09/1974.

(2) Los respectivos incisos refieren a las siguientes exigencias: a) que se haya fijado en forma expresa y por escrito el tiempo de la duración contractual; b) que las modalidades de las tareas o de la actividad, razonablemente apreciadas, así lo justifiquen.

(3) Hemos hecho referencia a los contratos modales más usuales, ello sin perjuicio de que existen otros dentro de nuestro ordenamiento, como las prestaciones por equipo, a tiempo parcial, o bien el régimen de contrataciones públicas a los que el derecho del trabajo puede alcanzar. 
Así, los límites que aquí denominados como de relativa consideración, se encuentran configurados por aquellas situaciones que, aun siendo imputables (al menos parcialmente) a una de las partes, se encuentran por fuera de las razones que conducen a tener por culminado de forma normal el vínculo contractual. A tenor ejemplificativo podemos citar, como ubicadas en este terreno, a la justa causal de extinción, a la incapacidad sobreviniente del trabajador, a la renuncia, al mutuo acuerdo rescisorio y a las razones económicas o de fuerza mayor.

Por contrapartida, el límite ordinario del contrato de trabajo por tiempo indeterminado de prestaciones continuas resulta ser la jubilación del trabajador, derecho que se puede declarar cuando se comprueba el cumplimiento de los recaudos legales exigidos en la especie, y que dan lugar, como lo veremos en las páginas que siguen, a dos órdenes de exigencias: el etario (edad) y el referente a la carga temporal (acreditación de años de servicios con aportes).

A su respecto, vale destacar que si el factor tiempo cumple una notable función en el desenvolvimiento de la relación laboral, dicho cometido se ahonda al hablar del contrato promovido por el legislador, ocasión en que, aún sin reconocérsele al trabajador privado - como regla - el derecho a la estabilidad en su puesto de trabajo, se fijan límites expresos e implícitos al denominado libre intercambio, a fin de colaborar para la celebración de negocios que supongan una continuidad en el cumplimiento de las prestaciones recíprocas que, por los caracteres de bilateralidad y conmutatividad, expresan el espíritu de un fundamental núcleo humano de mutuos beneficios.

Vinculado a dicha idea, el profesor Juan Carlos Fernández Madrid ha dicho que

El contrato de trabajo supone prestaciones sucesivas condicionadas a la naturaleza de la actividad de que se trate y a la organización de la empresa para la cual se trabaja. La prestación única y esencialmente fugaz es extraña a todo contrato de tracto sucesivo (2007, p. 851).

En la misma línea, y con una claridad notable, ha expresado el profesor Ángel Eduardo Gatti que: “(...) desde la perspectiva sociológica y también en orden a la óptica psicológica, el fenómeno del trabajo humano trasunta una voluntad social e individual de permanecer en forma continuada, durante la vida útil de trabajador" (2015, p. 195).

Como se ve, el contrato por tiempo indeterminado, a diferencia del resto de las tipologías reconocidas dentro de la ley 20.744, aun sin brindar (se reitera) estabilidad, colabora para que el dador de trabajo pueda proyectar su vida a partir de la expectativa de permanecer dentro del negocio celebrado hasta que adquiera las condiciones legales para poder acceder a la jubilación. 
EL SISTEMA DE COMPATIBILIDADES ENTRE EL TRABAJO Y LA JUBILACIÓN EN LOS ORDENAMIENTOS PREVISIONALES NACIONAL Y DE LA PROVINCIA DE BUENOS AIRES

\section{La jubilación como causal ordinaria de extinción del contrato de trabajo. El sistema nacional y la reforma de la ley 27.426}

En línea con lo manifestado en las páginas que anteceden, remarcamos que la jubilación constituye la causal normal de extinción del contrato por tiempo indeterminado. Ello aun cuando, por un descuido metodológico, nuestra Ley de Contrato de Trabajo estudie dicha figura en los últimos artículos del título referente a la extinción del contrato laboral.

A su respecto, vale señalar que la jubilación hace referencia tanto a un estado económico y social de la persona, así como también a un derecho de crédito por parte de su titular. Desde el primer aspecto, con el término de jubilado se engloban a las personas que, por ser comúnmente de avanzada edad, han dejado de prestar servicios en la economía laboral activa. Desde el segundo aspecto, y en una línea complementaria cualificada quizá por tener mayor rigor técnico en comparación con el anterior concepto, con el término jubilado o jubilada, se individualiza a una persona que, luego de cumplimentar los recaudos de edad y años de servicios, resulta declarada por un acto administrativo como titular de un derecho económico denominado beneficio previsional, que estará en directa relación con la actividad laboral desarrollada en la vida activa y con la cantidad de aportes comprobados al momento de solicitar el mentado beneficio.

En ese marco, la función de la jubilación adquiere un protagonismo destacable, escribiendo la doctrina especializada que la misma

(...) tiene por objeto cubrir económicamente las contingencias vejez e invalidez, creando beneficios pecuniarios a favor de las personas de avanzada edad o inválidas, que consiste en el pago mensual de una suma de dinero en proporción a la nómina salarial o renta presunta, y a las aportaciones realizadas al sistema con el fin de mantenerles, en principio, el status económico adquirido en la plenitud de la vida activa (Chirinos, 2009, p. 282).

Dicho lo anterior, abordaremos a continuación los recaudos generales existentes en el ordenamiento previsional nacional estructurado en la ley 24.241 (4) (en combinación con los elementos emanados de la Ley de Contrato de Trabajo), para luego, en un acápite aparte, proceder a efectuar una explicación del mismo estilo pero haciendo hincapié en la normativa general previsional de la provincia de Buenos Aires, el decreto ley 9650/80 (5).

(4) B.O. 18/10/1993.

(5) B.O. 30/12/1980. 
Siguiendo con la metodología antes trazada, diremos que, en el ordenamiento nacional, resulta de especial interés combinar lo prescripto por el artículo 19 de la ley 24.241, con lo estatuido por la LCT en sus artículos 252 y 253.

A su respecto, diremos que el artículo 19 antes mencionado, prescribe que tendrán derecho a la Prestación Básica Universal (PBU) y a los demás beneficios establecidos por esa ley, los afiliados que reúnan, de manera acumulativa, dos exigencias que, a tenor explicativo, pueden ser agrupadas como de carácter subjetivo -límite etario- y objetivo - años de servicios con aportes-. Respecto al primer elemento, la ley exige que los afiliados hombres hubieran cumplido sesenta y cinco años de edad, y las afiliadas mujeres sesenta años. En relación con la segunda exigencia, nuestro sistema previsional nacional requiere que se acrediten treinta años de servicios con aportes computables en uno o más regímenes comprendidos en el sistema de reciprocidad.

Explayándonos someramente respecto de las exigencias antes referenciadas nos parece importante remarcar una serie de cuestiones, encontrándose la primera vinculada al alcance que corresponde atribuirle a la denominada prestación básica universal o PBU. A su respecto, en coincidencia con lo escrito por los profesores Raúl Jaime y José Brito Peret, corresponde señalar que la prestación básica universal no es una única prestación consagrada con la finalidad de cubrir la contingencia vejez, sino el componente básico y uniforme del amparo económico a que se tiene derecho por haberse cumplimentado la edad exigida en nuestro sistema nacional (1996, p. 178).

Es decir, por un lado, tenemos la contingencia cubierta en la especie -vejez- y, por el otro, uno de los componentes constitutivos del beneficio tendiente a cubrir la misma. Los autores antes citados escriben a su respecto que "la PBU es básica porque constituye el componente primario indispensable para tener derecho, en su caso, a la prestación compensatoria (...) y a la prestación adicional por permanencia (...)" (1996, p. 178).

Siguiendo la línea elegida en los dos párrafos precedentes, diremos que, en un segundo aspecto, advertimos una connotación negativa en la diferenciación que la ley establece en cuanto a las exigencias etarias para que los hombres y las mujeres puedan jubilarse. En esa línea opinamos que tal distinción, en el tiempo que corre, no tiene razón de ser, o al menos no encuentra un justificativo lógico real en el cuerpo de la normativa nacional. Contrariamente, observamos que es una medida de discriminación vedada por el ordenamiento tanto específicamente laboral (artículos 17 y 81 LCT), como general (artículo 1, ley 23.592(6)); así como también

(6) B.O. 05/09/1988. 
EL SISTEMA DE COMPATIBILIDADES ENTRE EL TRABAJO Y LA JUBILACIÓN EN LOS ORDENAMIENTOS PREVISIONALES NACIONAL Y DE LA PROVINCIA DE BUENOS AIRES

por el supra legal (Convenio 156 de la OIT(7)), y el constitucional (artículos 16 CN; artículos 2 inciso 2, 3 y 9 del Pacto Internacional de Derechos Económicos Sociales y Culturales; artículo 26 del Pacto Internacional de Derechos Civiles y Políticos. Sin perjuicio de lo anterior, y con el mismo sentido legal tendiente a evitar dispensas discriminatorias de raigambre peyorativa que perjudiquen a la mujer trabajadora y también a la que quiere jubilarse, nos parece sumamente importante señalar que es una obligación fundamental del Estado, y de toda la sociedad, implementar (y respetar) políticas públicas serias que propendan a extender los derechos del personal femenino, ello a través de la materialización de acciones positivas cuyo sentido sea garantizar la igualdad real de oportunidades y de trato (conf. artículo 75 inciso 23 de la CN; artículo 7 inciso a) ap. i del PIDESC).

En un tercer aspecto, y en cuanto a la exigencia objetiva relacionada con los años de servicios con aportes, resulta importante remarcar que el sistema no pretende integrar este recaudo solamente con los servicios cumplimentados en la órbita nacional, sino que también pueden computarse, tal como lo prescribe el inciso c) del artículo 19 de la ley 24.241, los servicios con aportes desempeñados en uno o más regímenes comprendidos en el sistema de reciprocidad(8). Incluso, pueden formar parte del respectivo cómputo, servicios prestados en otros países, si es que hubiere mediado en el caso la firma de un convenio de reciprocidad internacional (9).

Prosiguiendo en el régimen nacional, y tal como lo adelantáramos párrafos atrás, es importante combinar el estudio del artículo 19 de la ley 24.241 con los artículos 252 y 253 de la Ley de Contrato de Trabajo.

(7) Convenio sobre la Igualdad de Trato entre Trabajadores y Trabajadoras, adoptado por la sexagésima séptima reunión de la Conferencia General de la Organización Internacional del Trabajo celebrada el 23 de junio de 1981, y aprobado por la República Argentina a través de la Ley 23.451 publicada en el Boletín Oficial el 14/04/1987.

(8) A su respecto es importante identificar el principio previsional de rol de caja otorgante, configurado por la cualidad jurídica asumida por la entidad previsional encargada de liquidar y abonar el beneficio jubilatorio, por haber sido la receptora de la totalidad o bien de la mayoría de los aportes efectuados en la vida activa. Por ejemplo, si una persona tiene mayor cantidad de años con aportes en ANSES (Nación), pero desea que dicha caja le contabilice también servicios desempeñados en la órbita provincial bajo el IPS, el sistema le permite "llevar a cómputo" al ámbito nacional aquellos servicios cumplidos en la órbita provincial, a los fines de engrosar la acreencia previsional. Y, como veremos más adelante, dependiendo de qué caja asuma el rol de otorgante, y de la naturaleza de los nuevos servicios, se puede pedir el reajuste de haberes por las prestaciones cumplimentadas con posterioridad al reconocimiento de la jubilación.

(9) Ejemplo de ello resulta ser el Acuerdo Multilateral de Seguridad Social del Mercosur, suscripto en Montevideo el 17 de Diciembre de 1997 entre Argentina, Brasil, Paraguay y Uruguay, y que fuera aprobado por la Ley 25.655, publicada en el Boletín Oficial el 16/10/2002. 
Como antes se dijo, la jubilación es el modo ordinario de extinción del contrato laboral por tiempo indeterminado. Es decir que, la indeterminación del plazo de tal tipología vincular, no da lugar a un nexo obligacional eterno, sino que, por el contrario, la finitud del mismo es un elemento a subrayar dentro de su singular estructura. Pero, a diferencia de los denominados contratos a plazo — de legal interpretación limitada tal como lo hemos puesto de manifiesto algunas páginas más arriba-, la continuidad es una regla que matiza el contrato promovido dentro de nuestro derecho individual. Y es que, como ya se ha remarcado también, el trabajador contratado bajo tal figura, ingresa a una organización productiva para poner su fuerza de trabajo a disposición de otro, con la expectativa de que va a permanecer en la misma hasta que adquiera las condiciones para poder jubilarse.

A su respecto, corresponde señalar que los artículos 252 y 253 de la LCT tipifican aquella forma ordinaria de extinción del vínculo jurídico laboral, normativa que a su vez fue parcialmente modificada por medio de la ley 27.426(10) en el año 2017. La variación más radical que matizó la normativa individual en referencia, impactó más que nada en el primer párrafo del artículo 252 que, luego de la reforma, extendió hasta los setenta años (sin distinción de sexos) el límite inicial a partir del cual se habilita al empleador a intimar al dependiente que cumpla las exigencias necesarias para poder acceder a la PBU, para que el mismo inicie los trámites jubilatorios, con la paralela obligación de extenderle los pertinentes certificados de servicios.

Es muy importante remarcar que, no obstante la modificación legal antes comentada, tal como lo señala el segundo párrafo del artículo 252 de la LCT, el trabajador y la trabajadora no pierden el derecho a solicitar el beneficio previsional con anterioridad a cumplir los setenta años, siempre que reúnan —esencial—, los recaudos legales subjetivos y objetivos analizados más arriba.

Sin perjuicio de ello, criticamos el nuevo límite de setenta años impuesto por la ley 27.426. Ello así pues, si bien como dijimos anteriormente, no se altera el derecho de las mujeres y hombres a solicitar su jubilación cuando hubieran adquirido las condiciones exigidas a su respecto por la ley previsional, eleva intencionalmente en cinco años (o diez en el caso de las trabajadoras que no opten por continuar prestando servicios hasta los sesenta y cinco años de edad, tal cual la facultad prescripta por el segundo párrafo del artículo 19 de la ley 24.241) el límite habilitante para que el empleador intime a iniciar los trámites jubilatorios. Luego, si tenemos en cuenta que los trámites previsionales del estilo suelen tardar a lo mínimo varios meses, y que según la OMS(11) la esperanza de vida para los

(10) B.O. 28/12/2017.

(11) Datos oficiales publicados por la Organización Mundial de la Salud en su sitio oficial disponible [on line] en el siguiente enlace: https://www.who.int/countries/arg/es/ 
EL SISTEMA DE COMPATIBILIDADES ENTRE EL TRABAJO Y LA JUBILACIÓN EN LOS ORDENAMIENTOS PREVISIONALES NACIONAL Y DE LA PROVINCIA DE BUENOS AIRES

hombres es de 74 años y 80 para las mujeres (según información registrada del año 2016), flaca protección se brindaría a las personas a quienes, si bien se les exige una cantidad prudencial de años de servicios con aportes, se les reconocería el derecho a percibir - como promedio - un beneficio ordinario efectivo entre cuatro y diez años (12), dependiendo del sexo. Creemos que el sistema actual da mayor prioridad a la financiación (con escasas rendiciones de cuentas) del sistema, antes que a la tutela continua y efectiva de las personas pertenecientes a la denominada tercera edad.

Acto seguido, luego de haber estudiado los recaudos subjetivos y objetivos para el goce de la jubilación en el ámbito nacional, tal como lo proyectáramos al inicio de este acápite, a continuación estudiaremos como se desenvuelve el sistema previsional de la provincia de Buenos Aires respecto a dicho tópico.

\section{Recaudos para el acceso a la jubilación ordinaria en la provincia de Buenos Aires}

Siguiendo con la idea de que la jubilación constituye la causal ordinaria de extinción del contrato laboral, y dentro del objetivo de este trabajo orientado a estudiar el sistema de compatibilidades entre los roles de trabajador y titular de un beneficio previsional, habiéndonos propuesto efectuar una comparación en cuanto a ese tópico entre los sistemas nacional y provincial, corresponde en este acápite estudiar los aspectos más destacables del terreno en donde campean aquellas condiciones legales para acceder al beneficio jubilatorio dentro de la sistemática del decreto ley 9650/1980.

Con el anterior propósito, cabe detenernos especialmente en lo preceptuado por el artículo 24 del cuerpo normativo antes citado. En líneas generales, corresponde identificar allí dos grupos de servicios. El primero, se encuentra constituido por los que podemos denominar como servicios comunes, y el otro grupo por los docentes.

Respecto al primer conjunto, el artículo 24 del decreto ley 9650/80 dice que tendrán derecho a la jubilación ordinaria los afiliados (refiere a los afiliados al Instituto de Previsión Social que, en el ámbito de la provincia de Buenos Aires, actúa como organismo de aplicación de la mentada normativa, conforme lo dispone el artículo primero), que hubieran cumplido sesenta años de edad y treinta y cinco años de servicios.

(12) Se parte para este análisis de la suposición consistente en que el trabajador o la trabajadora sigan prestando servicios hasta los setenta años, a lo que se suma la esperanza de vida para cada sexo (como se dijo, de manera aproximada, de 74 u 80 años). 
Y, en otro conjunto, ubicamos a los servicios docentes, grupo en el que a su vez se establecen una serie de diferenciaciones relacionadas con los recaudos legales exigidos para poder jubilarse. Así nos podemos encontrar - primero-con los docentes que hubieran cumplido tareas de manera directa frente a alumnos, o bien profesores con veinte horas cátedras en cualquiera de las áreas de la enseñanza, a quienes la ley les exige acreditar cincuenta años de edad y veinticinco años de servicios docentes. Y - segundo- nos topamos con quienes hubieran cumplido tareas de naturaleza técnico docentes (preceptores, integrantes de los gabinetes psicopedagógicos, bibliotecarios, directores, vicedirectores), a quienes la ley les exige para poder jubilarse, acreditar cincuenta y cinco años de edad y treinta de servicios.

En cuanto a la sistemática anterior, un detalle destacable en relación con la ley nacional 24.241, es que en el ordenamiento de la provincia de Buenos Aires no se establecen diferencias en cuanto al recaudo subjetivo etario para poder acceder al derecho jubilatorio. De esa manera, mujeres y hombres deben reunir, sin distinciones, los límites antes detallados. El dato analizado nos parece de suma relevancia y coloca, a nuestro entender, el sistema provincial por encima del nacional en tanto que, sin diferenciaciones de sexo, la normativa en tratamiento propende al desarrollo, sobre bases igualitarias, del pleno goce y ejercicio de los derechos reconocidos a nivel constitucional y legal.

Como antes se dijo, basándonos en el artículo 24 del decreto ley 9650/80, los servicios pueden ser catalogados, a los fines jubilatorios, como docentes o bien comunes. $\mathrm{Y}$, sobre esa base, también advertimos que para los servicios comunes las exigencias de edad y años de aportes son mayores (60 y 35 años respectivamente), mientras que para los docentes se requieren recaudos numéricos menos exigentes. Ahora bien, resulta útil destacar que, en realidad, un estricto apego a la técnica legal nos llevaría a conjugar en esa dicotomía a los servicios comunes con aquellos pertenecientes a los denominados regímenes diferenciales, siendo, respecto de estos últimos, los docentes una categoría especial. Es decir, habría otros servicios no comunes que tampoco son docentes (como los reconocidos en el artículo 25 del decreto ley 9650/80, correspondientes al personal de cuerpo de baile, a los que se les exige 40 años de edad y 20 de servicios con aportes para poder jubilarse). Sin perjuicio de ello, siguiendo la redacción del artículo 24, preferimos marcar la diferencia entre esos dos conjuntos - comunes y docentes- por ser los que mayor cantidad de casos originan en el ámbito previsional local.

Rige en el marco del decreto ley 9650/80, al igual que lo que ocurre en el ámbito previsional nacional, el sistema de la reciprocidad jubilatoria que implica la posibilidad de computar servicios cumplidos en una jurisdicción extraña a la que pertenezca la caja otorgante, siempre que se haya firmado al efecto el acuerdo 
EL SISTEMA DE COMPATIBILIDADES ENTRE EL TRABAJO Y LA JUBILACIÓN EN LOS ORDENAMIENTOS PREVISIONALES NACIONAL Y DE LA PROVINCIA DE BUENOS AIRES

respectivo. En este tema, cabe diferenciar dos tipos de carreras: la pura y la mixta, dependiendo dicha distinción de si una persona tiene la posibilidad de obtener un beneficio jubilatorio considerando los servicios prestados en su totalidad dentro de un mismo régimen jubilatorio, o bien si, caso contrario mediante, debe llevar a cómputo también servicios cumplidos bajo otro sistema previsional.

En este último caso, será individualizada como caja otorgante aquella en la que tenga mayor cantidad de aportes efectuados, y será identificada como caja reconocedora aquella en donde se encuentren ingresados aportes que -opcionalmente - desea también contabilizar para jubilarse. Como lo señalara la Dra. Rigoni: "la invocación de la reciprocidad jubilatoria es optativa para el afiliado pero si lo hace no puede parcializar carreras, es decir, deberá traer a cómputo todos los servicios prestados en las distintas jurisdicciones" (2008, p. 73).

\section{El mecanismo de compatibilidades entre el trabajo y la jubilación dentro del ordenamiento nacional. La regla}

Como ya hemos expuesto en páginas anteriores, el contrato por promovido o por tiempo indeterminado de prestaciones continuas regulado en la LCT se extiende hasta que el trabajador o la trabajadora se encuentren en condiciones de acceder a la jubilación.

A su respecto, diremos que todas las personas tenemos necesidades que debemos satisfacer a lo largo de nuestra vida. Una buena porción de ellas resulta cubierta -o pretende ser cubierta - por la remuneración o salario, que es uno de los elementos tipificantes del contrato de trabajo, regulado en sus notas más destacables dentro del artículo 21 de la LCT. Es el precio que el trabajador cobra al empleador por el hecho de poner su fuerza de trabajo a disposición del mismo, aun cuando este último no la utilice concretamente.

Ahora bien, llegada determinada edad —estatuida por los sistemas previsionales nacional y de la provincia de Buenos Aires, conforme ya fuera puesto de manifiesto antes-, la ley presume que se pierden ciertas condiciones psicofísicas para seguir trabajando, o bien que, luego de haber cumplido determinada cantidad de servicios, se adquiere el derecho a la cesación de los servicios y al goce de una jubilación.

Es decir que, cumplida determinada edad, y acreditados que fueran ciertos servicios con aportes ingresados al sistema, la jubilación viene a reemplazar la función que antes cumpliera el salario, o al menos se pretende que tal función sustitutiva sea satisfecha de buena forma. Así, se ha denominado a la jubilación como el salario de sustitución, señalado a su respecto la CSJN que: "la jubilación constituye la prolongación, después de la cesación regular y definitiva de la actividad 
social laboral del individuo, de la remuneración, como débito de la comunidad por el servicio que él ha prestado" (caso "Bercaitz, Miguel Ángel s/ Jubilación", sent. 13/09/1974, Fallos 289: 430, p. 437).

Sin perjuicio de lo anterior es dable señalar dos cuestiones. Por un lado, que la jubilación no siempre reemplaza exactamente de manera numérica al salario, ello desde que (salvo regímenes jubilatorios especiales), la tasa de sustitución del haber previsional ronda como promedio, entre el 70 y el 80 por ciento de la cuantía de la remuneración, ello sin perjuicio de que las necesidades vitales no solamente no se reducen, sino que en ocasiones pueden aumentar con el ingreso de las personas a la denominada tercera edad, derivado eso de la necesidad de nuevos servicios como medicación y la asistencia personal relacionada con el cuidado de personas ancianas o enfermas. Y, por el otro, que, aun cuando el sistema presuma que la persona ha perdido ciertas aptitudes al cumplir determinada edad, no en todos los casos media una sucesión material de la remuneración por la jubilación ya que, sea porque la jubilación no resulta suficiente para subsistir, o bien por un interés independiente de la persona, en ciertos regímenes se permite la acumulación de las condiciones de trabajador con la de jubilado. Esto último es lo que ocurre, dentro del sistema nacional, en la Ley de Contrato de Trabajo № 20.744 así como también en la de Jubilaciones y Pensiones No 24.241.

Para entender lo anterior, se deben conjugar dos artículos: el 253 de la LCT con el 34 de la ley de jubilaciones y pensiones. Éste último, prescribe que los beneficiarios de prestaciones del sistema previsional público podrán reingresar a la actividad remunerada tanto en relación de dependencia como en carácter de autónomo. Esta es la regla en el sistema previsional nacional, la de la compatibilidad entre los roles de trabajador y jubilado. Entonces, una misma persona puede acceder a una jubilación ordinaria si es que reúne las condiciones generales que ya hemos explicado antes, y ser, a su vez, trabajador, tanto en relación de dependencia o bien autónomo.

Sin perjuicio del derecho de acumulación reconocido expresamente por el ordenamiento nacional, surgen una serie de aristas problemáticas que corresponde analizar someramente.

El primer punto atañe a las obligaciones de los empleadores en caso de prestación de servicios en relación de dependencia por parte del jubilado, y consiste en constreñir a aquellos para que comuniquen el reingreso o la continuidad en la prestación de servicios a la autoridad de aplicación (ANSES - Administración Nacional de la Seguridad Social), con las formas que al efecto se establezcan, todo bajo apercibimiento de hacerlo pasible de una sanción de carácter pecuniario: una multa equivalente a diez veces lo percibido por el jubilado en concepto de haberes previsionales. Eso como obligación específica en caso de reingreso o continuación 
EL SISTEMA DE COMPATIBILIDADES ENTRE EL TRABAJO Y LA JUBILACIÓN EN LOS ORDENAMIENTOS PREVISIONALES NACIONAL Y DE LA PROVINCIA DE BUENOS AIRES

en el empelo luego de acceder al beneficio, lo que no obsta al cumplimiento de las obligaciones previsionales genéricas reguladas por el artículo 12 de la ley 24.241.

En la misma senda, los empleadores no se eximen de la obligación de depositar las correspondientes contribuciones, de la misma forma en que los trabajadores autónomos tampoco son excluidos de efectuar sus respectivos aportes, teniendo los mismos como fin engrosar las arcas generales del régimen previsional.

Relacionado con lo anterior, se vincula la obligación del trabajador dependiente de continuar efectuando - de forma semidirecta, ya que en este caso el empleador tiene la obligación de retener del salario bruto del obrero las sumas pertinentes - los aportes al régimen previsional, ello aun cuando el ingreso de los conceptos mencionados no da derecho a solicitar el reajuste del haber previsional original (conf. artículo 34, inc. 3 de la ley 24.241). Lo cual, según creemos, implica una notoria desventaja con el régimen previsional general de la provincia de Buenos Aires, conforme lo veremos más adelante.

Es decir, en el sistema previsional nacional, resultan compatibles, como regla, las posiciones de trabajador (autónomo o en relación de dependencia) con la de jubilado, más los aportes y las contribuciones que se efectúen con posterioridad al inicio del cobro de la jubilación no benefician directamente al trabajador, ya que éste no puede solicitarle a la ANSES el incremento de su haber considerando los nuevos desembolsos de dinero con destino a la seguridad social. Ello amén de que sí se recepta un beneficio para la colectividad (al menos en teoría), ya que los aportes depositados con posterioridad a la jubilación tienen como destino el Fondo Nacional de Empleo(13).

Combinando la ley 24.241, con lo prescripto por la Ley de Contrato de Trabajo - y relacionado esto con lo dicho anteriormente-, cabe apuntar algunas ideas en relación con el derecho a la antigüedad del trabajador. Como se debe saber en el punto, el artículo 18 de la LCT prescribe que

Cuando se concedan derechos al trabajador en función de su antigüedad, se considerará tiempo de servicio el efectivamente trabajado desde el comienzo de la vinculación, el que corresponda a los sucesivos contratos a plazo que hubieren celebrado las partes y el tiempo de servicio anterior, cuando el trabajador, cesado en el trabajo por cualquier causa, reingrese a las órdenes del mismo empleador.

(13) A su respecto, prescribe el artículo 145 inciso a) de la ley 24.013 (B.O. 17/12/1991, con la modif. de la ley 24.397 B.O. 29/06/1994): "Los recursos destinados al Fondo Nacional del Empleo son los siguientes: a) Aportes y contribuciones: (...) 5. Los aportes personales de los beneficiarios de prestaciones previsionales que reingresen a la actividad" (el entrecomillado no pertenece al original). 
Como se ve, tal cual lo hicimos al principio de este trabajo, traemos a cuenta nuevamente el elemento tiempo para comprender su incidencia en las arenas en que se ventilan los derechos del trabajador.

Dicho eso, una lectura literal de la normativa transcripta nos permitiría entender que la antigüedad del trabajador jubilado - a las órdenes, claro está, del mismo empleador-, se debería calcular considerando el período anterior al inicio del goce de la jubilación, así como también el tiempo cumplido en carácter de prestación de servicios con posterioridad a tal estado. Si perjuicio de ello, el artículo 253 de la LCT ha limitado esa conclusión prescribiendo literalmente que "(...) solo se computará como antigüedad el tiempo de servicios posterior al cese" (segundo párrafo). En el punto, creemos que la reforma de la ley 27.426 ha tratado de solucionar una vieja dicotomía que se daba en doctrina, y que apuntaba a dilucidar si el reingreso a las órdenes del mismo empleador debía ser con o sin solución de continuidad, es decir, si el trabajador debía cesar al menos un día y retomar sus tareas al siguiente, o bien si podía darse la ficción del cese laboral junto a la inmediata continuación del contrato y el pago de la remuneración, ello en orden a un nuevo acuerdo de partes. A su respecto el tercer párrafo del artículo 253 de la LCT reconoce la situación del trabajador jubilado que sigue prestando servicios a las órdenes del mismo empleador y, a tal efecto, también dice que se debe considerar la fecha del acuerdo de la prestación (jubilatoria) como inicio del cómputo de la antigüedad posterior al mismo.

Respecto de la antigüedad del trabajador jubilado, no sin algunos reparos, coincidimos con el criterio del legislador que contabiliza a sus efectos únicamente el período posterior al cese (14). Y en ello, no estamos de acuerdo con las posiciones que argumentan que se daría en el caso planteado, una renuncia o pérdida de derechos por el trabajador. Contrariamente a ello, creemos que no se materializa en el caso una verdadera renuncia de derechos, sino una acumulación de ellos. En efecto, la antigüedad devengada durante el tiempo anterior al cese le sirve al trabajador para comenzar a percibir la jubilación, ya que ese es un derecho que depende de dos tiempos: el personal etario, y el material vinculado al depósito de las contribuciones respectivas. Ahora bien, como ya lo adelantamos antes, con esto no justificamos la ausencia del derecho al reajuste por el cumplimiento de servicios posteriores al cese. Contrariamente a ello, entendemos que ese tópico del sistema nacional debe ser modificado siguiendo la pauta de la legislación previsional de la provincia de Buenos Aires.

(14) En el mismo sentido citamos, a tenor ejemplificativo, los siguientes precedentes: SCBA "Diani”, RI 117.908, sent. 03/09/2014; SCBA “Cachero”, L 112.734, sent. 20/03/2013; SCBA “Liptak Ghiloni”, L 87039, sent. 05/05/2010; CNAT Plenario 321 “Couto de Capa”, del 05/06/2009. 
EL SISTEMA DE COMPATIBILIDADES ENTRE EL TRABAJO Y LA JUBILACIÓN EN LOS ORDENAMIENTOS PREVISIONALES NACIONAL Y DE LA PROVINCIA DE BUENOS AIRES

\section{Las incompatibilidades reguladas como excepción en el sistema nacional}

Reiterando la idea general expuesta en el anterior apartado, diremos que en el sistema previsional nacional una misma persona puede, como regla, acumular el rol de trabajador con el de jubilado, ello con las aclaraciones que ya hemos sintetizado.

No obstante, en el marco de la ley 24.241, el artículo 34 señala dos excepciones a la regla de la compatibilidad ya explicada, una de carácter relativo y otra de carácter absoluto.

En relación con la primera, el inciso cuarto prescribe que los beneficiarios de prestaciones previsionales que hubieren accedido a las mismas amparados en regímenes diferenciales(15), instituido para quienes presten servicios en tareas penosas, riesgosas o insalubres, determinantes de vejez o agotamiento prematuro, no podrán reingresar a la actividad ejerciendo algunas de los servicios que hubieran dado origen a tal beneficio previsional; agregando, además, que, en caso de violación a dicho precepto, corresponde suspender el pago de los haberes correspondientes al beneficio previsional otorgado. Entonces, esta primera excepción es de carácter relativa porque no impide en todos los casos la acumulación de los roles de trabajador con el de jubilado, sino solamente en situaciones puntuales: como dice la norma y doctrina, cuando el titular del beneficio haya accedido al mismo al amparo de regímenes diferenciales. Luego, si un trabajador o una trabajadora se ha jubilado posteriormente a desempeñar tareas determinantes de vejez o agotamiento prematuro, el sistema no le permite continuar o reingresar a las mismas acumulando el beneficio jubilatorio con la remuneración, pero si los habilita para desarrollar otras de tipo no especiales. De todos modos, el objetivo directo del sistema no es impedir la continuación en el desempeño de tareas particularmente cualificadas por su riesgo, sino suspender (no cesar definitivamente) la obligación de pago del haber cuando se haya comprobado la continuación en las mismas tareas luego de haberse declarado el derecho a la jubilación.

Ahora bien, corresponde analizar si la norma exige que todos los servicios determinantes de la limitación parcial antedicha sean diferenciales o bien solamente

(15) La ley habla de "regímenes especiales" mas, siguiendo el criterio de los profesores Jaime y Brito Peret (1996), entendemos que, en rigor de verdad, la terminología correcta es la de "regímenes diferenciales", debiendo reservarse aquel solo para los casos en que el beneficio se conceda en atención a la particular situación o condición de los futuros beneficiarios (por ejemplo, cuando se acredita haber sido miembro de alguna de las tres funciones del Estado). Entonces, la noción "regímenes diferenciales", sería más objetiva que funcional, y a su vez más general (ejemplo, el caso del jubilado que desempeñó en la vida activa una tarea insalubre). 
una porción de ellos. Dentro de este tópico, el inciso cuarto del mentado artículo 34 exige que la jubilación haya sido otorgada "al amparo de regímenes especiales", pero no requiere, por contrapartida, que todos los servicios reúnan esa cualidad. De tal modo, según creemos, una persona bien puede jubilarse al amparo de un régimen más tutelar, habiendo cumplido en toda su vida laboral servicios cualificados como determinantes de vejez o agotamiento prematuro, o solamente en una porción de años. Y en los dos supuestos se daría lugar a la incompatibilidad relativa prescripta por la ley.

A su respecto, el derecho a la jubilación puede derivar del cumplimiento de servicios comunes (caso en el cual se deben acreditar los recaudos etario y referente a los años de antigüedad con aportes, conforme ya lo hemos analizado), o bien de tareas especiales que, por su mayor riesgo natural (trabajo desempeñado habitualmente en cámaras de frío, servicios vinculados con enfermedades infectocontagiosas, maquinista ferroviario, tareas relacionadas con la minería, entre muchas otras) dan lugar a un sistema más beneficioso para la persona trabajadora. Aquí, se debe tener en cuenta lo prescripto por el artículo 157 de la ley 24.241 según el cual los trabajadores comprendidos en los regímenes especiales (agregamos, de reconocimiento legal expreso) podrán tener derecho a percibir el beneficio ordinario luego de acreditar una edad y un número de años de aportes inferiores en no más de 10 años a los requeridos para acceder a la jubilación ordinaria por el régimen general.

Entonces, el "amparo" expresado por la norma - y que da origen a la incompatibilidad parcial que estamos explicando-, se puede dar luego de haber cumplido en toda la vida laboral anterior al inicio de los trámites jubilatorios, servicios encuadrados dentro de algún régimen diferencial, o bien solamente en una porción de los años requeridos para poder acceder a un haber previsional. Como se ve, la complicación se incrementa en este último caso puesto que, conforme lo delinea el artículo 157, los recaudos etario y de años de servicios con aportes se deben reducir hasta en diez años comparado con las exigencias vinculadas para los casos de tareas comunes que dan lugar a una jubilación ordinaria. Luego, de acreditarse una combinación de servicios comunes con otros diferenciales, se dará lugar a la operatoria pertinente por parte del organismo previsional que cumpla con el rol de ser caja otorgante tendiente a que, prorrateo mediante (el cual dependerá sobre todo de las leyes regulatorias de los regímenes específicos) se pueda determinar si una persona ha cumplido las exigencias legales para poder gozar de la jubilación lo cual, conforme lo expresamos, dará lugar en todo caso a la incompatibilidad relativa prescripta en el artículo 34 de la ley 24.241.

En otro tramo, nos encontramos con el sistema de la incompatibilidad absoluta, conforme al cual —escapando de la regla que permite, en la ley 24.241, la 
EL SISTEMA DE COMPATIBILIDADES ENTRE EL TRABAJO Y LA JUBILACIÓN EN LOS ORDENAMIENTOS PREVISIONALES NACIONAL Y DE LA PROVINCIA DE BUENOS AIRES

acumulación de la jubilación con la remuneración- se impide en todos los casos que se pueda dar lugar a la mentada combinación. De tal modo, el apartado quinto del artículo 34 prescribe que el goce de la prestación del retiro por invalidez es incompatible con el desempeño de cualquier actividad en relación de dependencia.

En primer término, corresponde dar a conocer los alcances técnicos que definen legalmente a la prestación del retiro por invalidez. En ese tramo, prescribe el artículo 48 de la ley 24.241 que tendrán derecho al retiro por invalidez, los afiliados que: a) se incapaciten física o intelectualmente en forma total, por cualquier causa, presumiéndose que tal alteración es total cuando la invalidez produzca en su capacidad laborativa una disminución del sesenta y seis por ciento (66 \%) o más, excluyéndose las invalideces sociales o de ganancias; b) no hayan alcanzado la edad establecida para acceder a la jubilación ordinaria, ni se encuentren percibiendo la jubilación en forma anticipada.

Como señala la normativa antes individualizada, a los fines de la determinación de la incapacidad se tendrán en cuenta los factores invalidantes de carácter psicofísicos, con prescindencia del estado de precariedad o desamparo originados en circunstancias de índole económica social o pérdida de la capacidad de ganancia. A su respecto, señalan Jaime y Brito Peret que

El legislador del SIJP ha puesto fin a la aplicación de pautas interpretativas de fuerte acento humanista pero quizá de excesiva amplitud para la determinación de la incapacidad laborativa, que admitían la incidencia de factores de la más diversa índole, y se ha inclinado por un criterio de exclusión de causales no estrictamente psicosomáticas, criterio que a nuestro juicio pretende dejar sentado el principio de que la prestación por invalidez no puede ser concebida como un sustituto del seguro por desempleo, distrayendo de esa manera fondos que tienen otro destino (1996, p. 289).

Con esta nueva regulación legal, pareciera que se ha dejado atrás un buen criterio defendido por la CSJN, en donde no se descartaba que frente a la inexistencia del 66\% exigido por la norma se pudiera reconocer la prestación por invalidez, cuando las incapacidades, aun siendo de menor grado, fuesen consideradas como relevantes(16).

(16) Puntualmente, nos referimos a la causa "Riveros" (Fallos 294:94), en donde la CSJN expresó que la exigencia de la disminución del $66 \%$ o más de la capacidad para el trabajo —necesaria legalmente para otorgar la jubilación por invalidez- no era un requisito ineludible y podía ser dejado de lado (consid. 7), afirmando además que cabía a los organismos previsionales ponderar razonablemente la posibilidad que cada afiliado tenía de sustituir la actividad habitual por otra compatible con sus aptitudes profesionales, ello teniendo en cuenta su edad, su especialización en la actividad 
Sin perjuicio de lo anterior, como señala la doctrina, a los fines de determinar el porcentaje de invalidez de una persona en miras al retiro bajo estudio, además de la incapacidad psíquica o psicofísica, se deben tener en cuenta también los denominados factores complementarios — edad y nivel de educación del requirente- - Y es de suma importancia decir que este criterio fue avalado también por la CSJN en un pronunciamiento bastante posterior al referenciado en el párrafo que antecede. Se trata de la causa "Melo Miguel Ángel c/Máxima AFJP s/ jubilación por invalidez ley 24241" (17), ocasión en que nuestro máximo Tribunal revocó un pronunciamiento de la Cámara Federal de la Seguridad Social (confirmatorio de un dictamen de la Comisión Médica Central) en cuanto había determinado que el peticionario no alcanzaba el $66 \%$ de incapacidad exigido por el artículo 48 de la ley 24.241 para acceder al retiro por invalidez. Expresamente la Corte señaló en directa referencia al limitado alcance impuesto por el inciso a) del artículo 48 de la ley 24.241 - que: "el apego excesivo al texto de las normas, sin apreciar las circunstancias particulares de cada caso, no se aviene con la cautela con que los jueces deben juzgar las peticiones vinculadas con la materia previsional" (consid. 7). Y, siguiendo con esa lógica, afirmó que el actor Sr. Melo cumplía con el requisito de invalidez exigido por la ley de fondo para acceder al amparo previsional tras ponderar especiales circunstancias del mismo, como su padecimiento físico, y la imposibilidad de sustituir su actividad habitual por otra compatible con sus aptitudes profesionales debido a su bajo nivel de instrucción (primario incompleto). Luego, en los tiempos que corren cabe efectuar una interpretación limitada de la exclusión de las denominadas, por nuestra ley previsional nacional, como invalideces sociales o de ganancias (18).

Acto seguido, nos abocaremos a estudiar brevemente el sistema de compatibilidad que surge de la prestación de invalidez.

Como antes fuera adelantado, el artículo 34 de la ley 24.241 prescribe también la denominada incompatibilidad absoluta - que se suma a la relativa dada en materia de tareas penosas, peligrosas e insalubres determinantes de vejez o agotamiento prematuro que antes fuera estudiada-, en cuyo marco, de lege lata, no se

ejercida, la jerarquía profesional que hubiera alcanzado, la naturaleza de la invalidez y las conclusiones del dictamen de grado (consid. 6).

(17) CSJN, sent. 24/08/2000.

(18) En similar sentido, pueden consultarse los siguientes precedentes de la CSJN: "Castillo Teófilo Marcelino c. ANSES", sent. 05/02/2008 (Fallos 331:72), y "Villagra Ramón Amado c/ Orígenes A.F.J.P., sent. 11/12/2007 (Fallos 330:5197, y dictamen), entre otros. Asimismo, de la Cámara Federal de Apelaciones de la Seguridad Social pueden consultarse - entre muchos otros-, los siguientes precedentes: "Zarza Claudia Elizabeth c/ ANSES s/ retiro por invalidez (art. 49 P.4 LEY 24.241)", sent. 30/09/2014 (Sala II); “Ocampo Raúl c/ Siembra AFJP s/ Prestaciones varias", sent. 18/10/2007 (Sala I). 
EL SISTEMA DE COMPATIBILIDADES ENTRE EL TRABAJO Y LA JUBILACIÓN EN LOS ORDENAMIENTOS PREVISIONALES NACIONAL Y DE LA PROVINCIA DE BUENOS AIRES

puede acumular el goce del beneficio de retiro con la condición de ser trabajador o trabajadora en relación de dependencia. Es decir, según la ley, la percepción del retiro por invalidez y una remuneración paralela serían incompatibles.

Sin perjuicio de lo anterior, en la jurisprudencia se han ventilado criterios afortunadamente más amplios que el que surge de la ley previsional nacional. A su respecto, nos encontramos con el precedente "Franchi" (19) de la CSJN, en donde nuestro Superior Tribunal Nacional dejó sin efecto una sentencia dictada por la CNAT confirmatoria de una resolución administrativa que había suspendido el pago del beneficio de jubilación por invalidez tras considerar que mediaba una incompatibilidad entre la percepción de esa prestación y la vuelta a la actividad en relación de dependencia, así como también la no aplicación al caso de la ley que sistematizaba un mecanismo especial de protección para las personas con discapacidad. Se trató el caso enunciado, de un supuesto recaído bajo el imperio de la ley 18.037 (20) — predecesora de la ley 24.241—, y de un trabajador retirado por invalidez pero que, no obstante, pretendía reintegrarse a la actividad para desarrollar tareas en Ferrocarriles Argentinos, ocasión en la cual nuestro Superior Tribunal sostuvo que establecer en materia de compatibilidad dos regímenes distintos, uno respaldado por la ley 18.037 -jubilatoria del personal dependiente y que impedía la acumulación de los roles de trabajador con la de jubilado- y otra avalada por la ley 22.431 -régimen especial de protección de las personas con discapacidad, que contenía una disposición contraria a la anterior, en el sentido de permitir la acumulación de beneficios en los porcentajes establecidos por la reglamentación, sistema al que fueron invitadas las provincias para sancionar en sus jurisdicciones regímenes normativos análogos a dicha ley conforme su artículo 27-, tenía por virtualidad crear una situación desigual entre las personas declaradas discapacitadas por diferentes organismos del Estado Nacional, contrariando la lógica de los sistemas de protección frente a la discapacidad, que no era otra que propender a lograr un mayor bienestar de las personas que sufren una disminución física o intelectual. En resumen, en el caso referenciado, la CSJN avaló la acumulación de beneficios tras considerar que el trabajador estaba capacitado para desarrollar tareas laborales, no obstante, su situación permanente de discapacidad.

Seguidamente, citaremos otro precedente de la CSJN, el caso "Guarino" (21). En el mismo, el Sr. César Dante Guarino había obtenido en febrero del año 1994

(19) CSJN, "Franchi, Héctor Laerte s/jubilación", sent. del 03/07/1990 (publicada en la colección de Fallos 313:579).

(20) B.O. 10/01/1969.

(21) CSJN, "Guarino Cesar Dante c/ ANSES s/ restitución de beneficio - medida cautelar", sent. 14/04/2009 (publicado en la colección de Fallos 332:850). 
un retiro por invalidez, cesando en su desempeño laboral como personal bancario, tras constatarse que adolecía de una incapacidad del $70 \%$ de la total obrera. Posteriormente a dicho evento, el actor reingresó a las tareas laborales, pero esta vez desarrollando actividades como docente, suceso que se extendió hasta marzo de 1995. Constatado ese hecho por los organismos previsionales administrativos, se le dio de baja el inicial beneficio de retiro, decisión que fue parcialmente confirmada por la primera y segunda instancias judiciales, ocasiones en las cuales se determinó que el actor tenía derecho a gozar del retiro por invalidez, pero desde la fecha en que hubiera cesado de cumplir sus tareas docentes. Contra ese decisorio el actor dedujo recurso extraordinario, argumentando que no correspondía otorgarle un nuevo retiro por invalidez, ya que el obtenido a partir de febrero de 1994 debía subsistir a pesar de haber continuado prestando servicios como docente hasta marzo de 1995, y que la percepción de dicho beneficio no se encontraba reñida con su desempeño como profesor, ya que tales labores habían sido realizadas con su capacidad restante. La Corte, tras constatar que el actor, no obstante su capacidad reducida, podía desarrollar actividades docentes (ya que las mismas se llevaban a cabo en una jornada limitada, y las remuneraciones obtenidas con dichas laboras no constituían un medio ponderable de vida), revocando las sentencias recaídas en las instancias anteriores que habían ordenado otorgar al reclamante un nuevo beneficio, no negó absolutamente la compatibilidad entre los roles de trabajador con el de jubilado por retiro, diciendo que, en todo caso, las normas sobre incompatibilidad existentes autorizaban a aplicar contra el Sr. Guarino los cargos respectivos, mas no la extinción del inicial haber. En esta senda, afirmó que dichos cargos solo resultaban procedentes en la medida en que el monto de su jubilación por invalidez excediera el importe fijado por las normas de compatibilidad limitada (22). En pocas palabras, la Corte no negó la compatibilidad reclamada, aunque sí avaló la formulación de cargos, mas solamente en los porcentajes admitidos por la ley.

Finalmente, citaremos un fallo de la Suprema Corte de Justicia de la provincia de Buenos Aires. Se trata del precedente "Barragán" (23) en donde la Corte, por mayoría de votos, hizo lugar al recurso incoado por el actor contra la sentencia dictada por el tribunal de trabajo que había desestimado el cobro de las indemnizaciones laborales derivadas de la extinción del vínculo que lo había unido a la

(22) A su respecto, vale señalar que la ley 18.037 - modificada en este tramo por la ley 22.431 (artículo 17)—, en su artículo 65 prescribía que: "Percibirá la jubilación por invalidez hasta el importe de la compatibilidad que el Poder Ejecutivo fije de acuerdo con el inciso b) del artículo anterior, el beneficiario que reingresare a la actividad en relación de dependencia por haberse rehabilitado profesionalmente. Esta última circunstancia deberá acreditarse mediante certificado expedido por el órgano competente para ello" (las comillas no pertenecen al original).

(23) SCBA, caso "Barragán, Mario Argentino contra Taberna Hnos. Indemnización por despido" (causa L 98.663, sent. del 05/06/2013). 
EL SISTEMA DE COMPATIBILIDADES ENTRE EL TRABAJO Y LA JUBILACIÓN EN LOS ORDENAMIENTOS PREVISIONALES NACIONAL Y DE LA PROVINCIA DE BUENOS AIRES

demandada. Se discutieron allí diversas cuestiones relacionadas con la carga de la prueba del contrato laboral, íter en el que - sobre todo en un enjundioso voto de la ministra Dra. Kogan-, se efectuó una correcta (a nuestro modo de ver) interpretación del instituto de la presunción laboral receptada en el artículo 23 de la LCT. En el caso, el Sr. Barragán, luego de prestar servicios para la demandada durante septiembre de 1980 y abril de 1982, y de obtener un retiro por invalidez a raíz del accidente de trabajo sufrido tiempo antes de la extinción del vínculo (mayo de 1981), reingresó a prestar servicios a favor del mismo empleador, más su reclamo fue articulado a raíz de la negativa patronal de regularizar su nuevo contrato. Temas procesales mediante - que por la entidad de este trabajo se dejan de lado-y de reconocerse, por mayoría, que había mediado en la especie un verdadero vínculo laboral, con base en el encuadre legal trazado por la ley 18.037 - que, como vimos, también establecía la regla de la incompatibilidad entre retiro por invalidez y desarrollo de actividades en relación de dependencia-, se dijo, con referencia al caso "Franchi" antes tratado, que

(...) sería de total injusticia si, estando capacitado física y psíquicamente para realizar otras tareas ajenas a las circunstancias que provocaron su invalidez, no las pudiera ejercer por el hecho de estar jubilado por discapacidad, dados los principios tuitivos de la normativa previsional (punto IV. 2, voto de la Dra. Kogan).

Y, no obstante tener a vista la regla de la incompatibilidad, reconoció el derecho indemnizatorio reclamado por el actor, considerando que, en todo caso, una norma prohibitiva como la que fijaba la imposibilidad de acumular beneficios, estaba dirigida al empleador, y no podía afectar, en orden a lo prescripto por el artículo 40 segundo párrafo de la LCT, los derechos devengados por el trabajador reclamante.

Como se ve, la aparente regla en la normativa nacional que hace referencia a la incompatibilidad absoluta entre la percepción de un retiro por invalidez y el desempeño de una actividad en relación de dependencia, debe necesariamente ser revisada - y matizada, claro está, en cada reclamo- a la luz de las ideas que, con el método de casos, tratamos de sintetizar en los párrafos que anteceden. Por otra parte, corresponde recordar - y le sirve a la persona trabajadora tenerlo muy en cuenta-, que la incompatibilidad legal impide acumular un beneficio por invalidez y un trabajo en relación de dependencia. Mas, por exclusión, dicho impedimento no obsta a que una persona que hubiera accedido al retiro explicado pueda desarrollar labores como trabajador autónomo.

En resumen, en materia de compatibilidad, y según la letra fría de la ley 24.241, quien se encuentre gozando de un retiro por invalidez no podrá ser, a la vez, trabajador en relación de dependencia. Sin perjuicio de ello, sabemos que existe nutrida 
jurisprudencia que ha dicho lo contrario (tal como ya hemos escrito antes), y, por ende, debemos también tener en cuenta esos criterios más amplios. En la misma senda, vale destacar que el retirado por invalidez sí podrá ejercer (porque la ley no lo impide) prestaciones laborales, pero como autónomo. Como se advierte, la mentada incompatibilidad absoluta se relativiza a poco que investigamos su estructura y las interpretaciones dadas a su respecto. Recordamos que nuestra CSJN ha dicho que, en materia de seguridad social, el rigor de los razonamientos lógicos debe ceder a fin de que no se desnaturalicen los fines superiores que la informan(24).

\section{Las compatibilidades previsionales en la provincia de Buenos Aires. Algunas comparaciones con el régimen nacional}

Estudiaremos en este apartado los rasgos más sobresalientes que existen, en el marco del decreto ley 9650/80, respecto al puntual instituto de la compatibilidad previsional que titula este trabajo.

De base, diremos que median notables diferencias entre el régimen provincial, y el nacional que ya ha sido tratado. La fundamental (y de raigambre negativa) es que, si en el sistema previsional nacional estructurado a través de la ley 24.241 la regla en materia de compatibilidad resulta ser la posibilidad de acumular la percepción de una jubilación con una prestación laboral y su correspondiente remuneración - ya sea como autónomo o bien en relación de dependencia-, en la sistemática del decreto ley $9650 / 80$ se prescribe, como regla, una situación contraria. En efecto, como lo regula el artículo 60, primer párrafo, resulta incompatible la percepción del haber jubilatorio con el desempeño de cualquier actividad en relación de dependencia. Claro que, al igual que lo que ocurre en nación, dentro del sistema previsional más importante a nivel local (por la gran cantidad de personas a las que el mismo abarca) existe en el caso una importante excepción: el ejercicio de la docencia. Ello sin perjuicio de que se permita otra acumulación, pero esta vez cuando se trate de trabajadores autónomos.

En pocas palabras, en el régimen previsional general de la Provincia de Buenos Aires, si bien no se permite - como regla - acumular los roles de jubilado y trabajador dependiente, se limita esa exclusión en el caso de la docencia (25), y se deja abierta la posibilidad de acumulación para los casos de trabajo autónomo.

(24) CSJN, caso "Lenta, Dominga s/ Jubilación”, sent. 12/03/1987.

(25) Vale agregar aquí el caso de las personas que se jubilan directamente como docentes —actividad reglada a través del Estatuto del Docente, vertebrado en la ley provincial № 10.579 (B.O. 30/02/1987)—, a quienes, como regla, se les permite acumular el haber previsional con la remuneración también fruto del nuevo ejercicio docente. 
EL SISTEMA DE COMPATIBILIDADES ENTRE EL TRABAJO Y LA JUBILACIÓN EN LOS ORDENAMIENTOS PREVISIONALES NACIONAL Y DE LA PROVINCIA DE BUENOS AIRES

Sin perjuicio del elemento negativo antes referenciado, siguiendo con el confronte propuesto, el sistema previsional de la provincia de Buenos Aires tiene una notable ventaja en comparación al nacional, traducida la misma en la posibilidad que tiene la persona que continúa o bien reingresa a la actividad luego de haberle sido reconocido su derecho jubilatorio, de solicitar el reajuste de su haber previsional, claro está, siempre que no se haya violado el sistema de compatibilidades establecido en Provincia. Recordemos que, en el ámbito nacional, los aportes y contribuciones derivados de una prestación cumplimentada por un jubilado, se dirigen a engrosar el sistema del Fondo Nacional de Empleo, mas no dan lugar a reajuste alguno.

En relación con la posibilidad de reajustar el haber previsional en la Provincia -que se denomina como reajuste por reingreso, y se regula por el artículo 53 del decreto ley 9650/80-, corresponde decir dos cosas importantes. Primero, que dicho reajuste, deriva de los nuevos aportes y contribuciones efectuadas (en el marco legal), con posterioridad al reconocimiento jubilatorio inicial. Y, segundo, que ese reajuste se dará únicamente cuando la persona jubilada que reingrese o continúe en la vida laboral desempeñe un cargo de mayor jerarquía (debiéndosele, según creemos, otorgar prioridad al dato de ser mejor remunerado), ya sea en el ámbito provincial como nacional, siempre que lo hubiera cumplido un tiempo consecutivo mínimo de tres años para los casos de desempeño en un solo cargo de mayor jerarquía, o bien un año cuando se hubiera acreditado, con posterioridad a la jubilación, haber ocupado más de un cargo de iguales características. En este último caso, es derecho del particular optar por el cargo a partir del cual va a requerir - por reingreso- la mejora de su jubilación.

Amén del reajuste indicado, y en el punto específico de las compatibilidades, es necesario tener en cuenta el conjunto de formalidades que rodean a la posibilidad de peticionar al IPS (Instituto de Previsión Social) el incremento de un haber en orden a las nuevas tareas que puedan cumplirse con posterioridad a que haya sido reconocido el inicial derecho previsional.

A su respecto, una vez reconocido el derecho jubilatorio en la provincia de Buenos Aires - a través del acto administrativo dictado por el Directorio del IPS-, si una persona desea continuar o bien reingresar a las tareas laborales (ya sea para el mismo o bien para otro empleador, en iguales o bien en diferentes tareas) debe poner dicha circunstancia en conocimiento de la autoridad de aplicación dentro del plazo de treinta días corridos a los fines de que, analizado el sistema de compatibilidad en el caso puntual del sujeto requirente, se determine la posibilidad de seguir percibiendo la jubilación o bien, caso contrario, se suspenda la misma hasta que la persona jubilada cese en la prestación de servicios posteriores al reconocimiento previsional. 
Mas, si se omitiere en el caso perfeccionar la comunicación que obligatoriamente establece el artículo 60 del decreto ley 9650/80, la consecuencia es doblemente negativa para el particular: por un lado, el IPS estará habilitado para generarle un cargo deudor (26) por las sumas que el titular del beneficio recibió en contravención al régimen local de compatibilidad y, por el otro, los servicios cumplimentados en violación a la ley no darán derecho a solicitar el reajuste del haber previsional, al menos hasta que se regularice la situación del caso.

Sin perjuicio de lo anterior, corresponde señalar que, por violación al sistema de la compatibilidad provincial, como regla no se pierde el derecho al haber previsional inicialmente reconocido, sino que solamente se puede dar lugar a las dos consecuencias negativas anteriormente señaladas. En efecto, tal como indica el artículo 60 en su inicio, a todo evento, la incompatibilidad puede afectar la percepción del haber, pero no el derecho al mismo. Luego, si una persona continúa en la actividad o bien reingresa al trabajo, sin cumplimentar el aviso legal antes mencionado, no obstante ser infractor, no perderá el derecho al haber jubilatorio, más si se habilitarán los mecanismos ejecutivos pertinentes (cargo deudor, cuyo trámite está regulado puntualmente en el artículo 61 del decreto ley 9650/80), y se perderá como se dijo el derecho al reajuste por los nuevos aportes efectuados en violación a la ley.

Tal como se expresó antes, la infracción al ordenamiento previsional no supone como regla la pérdida del derecho. Sin embargo, ponemos de resalto que existen, en el decreto ley 9650/80, dos importantes excepciones a lo antes señalado.

La primera refiere al caso de los beneficios previsionales otorgados luego de haberse determinado la incapacidad de una persona trabajadora. En ese tramo, el artículo 64 establece en su inciso b) que el derecho a la prestación se pierde cuando el particular desempeñare cualquier actividad en relación de dependencia, fijando, como importante excepción, el reingreso al resguardo de los regímenes especiales que amparan a las personas con discapacidad.

En tanto que la segunda excepción a la regla que indica que no se pierde el derecho por violar el régimen de compatibilidades establecido a nivel provincial, se encuentra prescripta en el artículo 65 inciso d). El mentado precepto, refiere

(26) Los cargos deudores son una declaración — con carácter de ejecutividad-, que un organismo efectúa contra determinada persona, dentro de un acto administrativo, y por un período y monto específico. Se suceden cuando se ha determinado que un sujeto cobró, sin causa legal, cierta suma de dinero, y sirven para que el particular devuelva (llegado el caso, coactivamente) los montos percibidos de forma indebida. La SCBA ha fijado dos recaudos para la legitimidad de los cargos deudores: primero, que tenga respaldo en un acto administrativo; $y$, segundo, que se materialice dentro de los dos años de advertido el error por parte del IPS (SCBA, "Acosta”, B 65758, sent. 31/10/2016). 
EL SISTEMA DE COMPATIBILIDADES ENTRE EL TRABAJO Y LA JUBILACIÓN EN LOS ORDENAMIENTOS PREVISIONALES NACIONAL Y DE LA PROVINCIA DE BUENOS AIRES

al caso de los haberes de pensión que hubieran sido otorgados en relación con la carencia de bienes por parte del sujeto peticionante y, en materia de incompatibilidad, establece que el beneficio de pensión se extingue (entre otros supuestos) cuando el titular reingresare a una actividad remunerada, cambiando, por ende, el marco fáctico sobre el que se asentó su inicial petición.

En cuanto a la incompatibilidad entre el retiro por invalidez y la percepción de remuneraciones derivadas del desarrollo de una actividad en relación de dependencia, es útil estar al criterio expreso por la SCBA en los autos "Milocco" (27) en donde, por mayoría de votos, se terminó que la jubilación por incapacidad no podía entenderse como un beneficio de carácter extraordinario o de interpretación estricta - "pues ello implica tanto como afirmar que tal prestación resulta un privilegio" (punto II del voto del Dr. Negri)—, y que resultaba parcialmente procedente el cargo deudor declarado legítimo contra la actora puesto que la misma, al reingresar a la actividad como docente luego de haber obtenido un retiro provisorio por invalidez a raíz de una relación laboral prestada a favor de la DGCyE (Dirección General de Cultura y Educación) había contrariado la normativa local que establecía la incompatibilidad entre el mentado retiro y la remuneración. De todos modos, es útil observar que en este precedente también se tuvieron en cuenta otros elementos, valorados todos ellos a la luz de los amplios criterios propios de la seguridad social. El principal, y que motivara el decisorio al que adhirieron la mayoría de los ministros, se asentó en el análisis del valor respaldatorio dado a los dictámenes médicos que determinaron la evolución de capacidad laborativa de la reclamante, y el respeto al derecho de defensa de la misma en el tránsito entre su dictado y posterior aplicación. En dicho tramo, declarándose legítimo el cargo deudor solamente por un período de tiempo a raíz del desempeño contra legem de relaciones laborales estando percibiendo un retiro por invalidez, se lo rechazó respecto de otro período en que, sin la fundamentación pertinente, se había determinado que la actora había recuperado parte de su capacidad laboral. De ese modo - si bien la Corte entendió que, en la especie, la aplicación del artículo 64 inciso b) del decreto ley 9650/80 conllevaba el reconocimiento de una excepción respecto a la regla de la compatibilidad señalada en el artículo 60 en relación con el goce de un beneficio jubilatorio y el desempeño de tareas docentes, considerando que no podía admitirse que se continúe o recomience la misma labor por la cual se había catalogado a una persona como inválida-, afirmó que el IPS no pudo formular válidamente un cargo pecuniario a la actora, cuando tanto el propio organismo previsional, así como también los organismos asesores, por la falta de uniformidad en los exámenes médicos realizados, no tenían certeza acerca de la invalidez que padecía la reclamante.

(27) SCBA, autos "Milocco, Laura Amelia contra provincia de Buenos Aires (Instituto de Previsión Social). Demanda contencioso administrativa", causa B. 63.845, sentencia del 25/11/2009. 
En otra senda, nos encontramos con el precedente "Cal Herbertz" (28) también de la SCBA, en donde el Superior Tribunal de la Provincia de Buenos Aires tuvo que entender en un reclamo articulado por una trabajadora retirada de la Municipalidad de Avellaneda (repartición en la cual había prestado servicios por veinte años, durante el período 01/10/1958 al 15/02/1979), por padecer de secuelas derivadas de una poliomielitis en ambas piernas, agravadas por traumatismos y uso de bastón; y determinársele, en razón de dicha circunstancia, una incapacidad para desarrollar sus tareas habituales. El debate sustancial - que giró en derredor de la pretensión anulatoria con reconocimiento de derechos articulada por la reclamante-, se materializó a raíz de la decisión del IPS (caja otorgante) de darle de baja su retiro de invalidez, tras constatarse que la actora, Sra. María de los Dolores, desarrollaba una tarea remunerada: docente en un establecimiento municipal dedicado a la atención de personas con discapacidad. Lo que peticionaba la reclamante era la anulación del acto por el que se había revocado su beneficio de retiro y el pago retroactivo de las sumas dejadas de percibir. Para ello, sostuvo que su caso se encuadraba dentro de la excepción contenida en el artículo 64 inciso b) del decreto ley 9650/80, en tanto los servicios docentes cumplimentados con posterioridad a su retiro por invalidez se encuadraban en el régimen tutelar de las personas con discapacidad (Régimen Jurídico Básico para las Personas discapacitadas establecido por la ley 10.592, reglamentada por el decreto 1149/90, y parcialmente modificada por la ley 10.593). La SCBA hizo lugar al planteo articulado, considerando que su incapacidad para el desarrollo de lo que fuera su actividad habitual desde 1958 a 1979 no había impedido que, en la medida de sus capacidades residuales, desempeñase una actividad docente; y que, la no inclusión de la actora en el régimen especial desde el inicio de sus tareas docentes en beneficio de la comuna identificada, resultaba un incumplimiento de su empleador que en ninguna medida podía perjudicarla. En esta amplia protección, aclaró que de lo que se trataba era de la inserción en la vida activa de las personas con una discapacidad que, no obstante, no les impedía prestar, como en el caso, un servicio útil para el Estado. Entendió, entonces, que atento las especiales circunstancias de la actora, no correspondía aplicar a su caso, el supuesto de la incompatibilidad absoluta entre la jubilación y el nuevo empleo consagrado en la primera parte de artículo 64 inciso b) del decreto ley 9650/80 sino, eventualmente, la figura limitada del artículo 60.

Como se advierte de la síntesis normativa y jurisprudencial efectuada, en materia de compatibilidad previsional, existen marcadas diferencias entre el sistema nacional y el de la provincia de Buenos Aires que es importante tener en cuenta a la hora de comprender las cualidades definitorias de cada uno de ellos y, sobre lo

(28) SCBA, autos "Cal Herbertz, María de los Dolores contra Provincia de Buenos Aires (Instituto de Previsión Social). Demanda contencioso - administrativa”, causa B. 58.854, sent. del 16/08/2000. 
EL SISTEMA DE COMPATIBILIDADES ENTRE EL TRABAJO Y LA JUBILACIÓN EN LOS ORDENAMIENTOS PREVISIONALES NACIONAL Y DE LA PROVINCIA DE BUENOS AIRES

dicho, poder reclamar los derechos que se puedan ver conculcados en los casos particulares.

\section{Conclusiones}

Luego de todo lo escrito, nos pareció importante escribir una serie de conclusiones.

Como fuera ya mencionado, trabajador y empleador se unen —en el marco del derecho social - a partir de un nexo obligacional que puede adquirir diversas características jurídicas. Son las denominadas tipologías contractuales.

De todas ellas, la Ley de Contrato de Trabajo otorga prioridad o prevalencia solamente a una, y la individualiza como el contrato de trabajo por tiempo indeterminado de prestaciones continuas.

Si bien el factor tiempo es un elemento común de todas las formas jurídicas con que se pueden unir quienes celebran una relación laboral, el mismo adquiere contornos especiales en el denominado contrato por tiempo indeterminado.

En el mismo, el trabajador, aun sin derecho a la estabilidad en su puesto, tiene, sin embargo, la expectativa de continuar prestando servicios hasta que cumplimente las condiciones subjetivas y objetivas para poder jubilarse.

En ese tramo, la jubilación resulta ser el modo ordinario de extinción del contrato jurídico laboral y nace, a partir de una conexión entre el derecho del trabajo y el de la seguridad social, cuando, por imperio de esta última rama, el ordenamiento previsional presume que las personas, por disminución de sus capacidades psicofísicas, deben dejar de prestar servicios para comenzar a gozar del beneficio por el que han aportado toda su vida activa.

Si bien se dice que la jubilación es un salario de sustitución —porque viene a reemplazar las funciones de manutención que, durante la vida laboral, cumplía el salario- no siempre media un reemplazo numérico de uno por el otro, o bien en ocasiones tampoco se concreta una sustitución material en la especie.

De esa forma, no en todos los casos la jubilación reemplaza al salario, ya sea porque la cuantía de aquella resulta menor, o bien porque la persona que se jubila también desea continuar trabajando.

Dentro de ese tema, se da paso al sistema de compatibilidades entre el trabajo y la jubilación que se bifurca en dos grandes modelos: el régimen previsional 
nacional - ley 24.241 - que, como regla, permite la acumulación; y el de la provincia de Buenos Aires - decreto ley 9650/80 - que sigue como norte una solución opuesta.

Así, la ley 24.241 permite como regla que se pueda acumular, en una misma persona, el salario y la jubilación. Mas reconoce también dos incompatibilidades: la absoluta, rectora de la no acumulación, que se da en los casos en que una persona hubiera accedido a un beneficio de retiro por invalidez y, a la misma, el sistema jurídico le impide reingresar a la actividad en relación de dependencia; y la relativa, que impide que quien se hubiere jubilado al resguardo de un régimen diferencial, continúe o bien se reincorpore a la misma actividad luego de que le es declarado el derecho.

Por su parte, el decreto ley 9650/80 prescribe como regla la no acumulación entre el salario proveniente de una relación de dependencia, y la jubilación. Si perjuicio de ello, vertebra también dos casos especiales: el ejercicio de la docencia y los trabajos autónomos. A su respecto, para el reingreso - que puede ser con o sin acumulación dependiendo del caso (se reitera que la acumulación es aquí la excepción)—, exige condiciones especiales a los fines de evitar ciertas sanciones reguladas en el derecho previsional provincial.

Como se ve, dos ramas que por sí mismas son autónomas - el derecho del trabajo y el de la seguridad social- encuentran importantísimos puntos de conexión y relación.

El ensamble que existe entre ellas permite vertebrar y comprender el conjunto de instituciones que se fueron construyendo a lo largo de la historia y que tuvieron por fin regular las consecuencias derivadas de un contrato de trabajo que fue, que es y que será.

En esta investigación hemos tratado de sintetizar ciertas relaciones jurídicas entre componentes que usualmente se estudian por separado por una cuestión de orden metodológico, pero que requieren, sin embargo, una conexión y reflexión permanentes.

No obstante que estas páginas se encuentran escritas más que nada a la luz del derecho de la seguridad social, se pretendieron reflejar las profundas vinculaciones que se dan en lo cotidiano entre dos ramas autónomas pero que encuentran en la materia del derecho social un engranaje claro y un enriquecimiento recíproco.

En esa línea, comprendemos que el estudio de los diversos institutos que se nos abren desde el espectro disciplinar seleccionado es fundamental para poder capacitarnos en una realidad compleja y diversificada. 
Ante ello, la función de los operadores jurídicos supone un compromiso permanente que exige, además de la actualización legal positiva, un entendimiento y aplicación cotidiana de los valores perennes que informan, desde su nacimiento, el rol tutelar del derecho social.

\section{Bibliografía}

Chirinos, B. (2009). Tratado de la Seguridad Social. Buenos Aires: La Ley.

Etala, C. A. (2008). Derecho de la Seguridad Social. Buenos Aires: Astrea.

Fernández Madrid, J. C. (2007). Tratado Práctico de Derecho del Trabajo. Buenos Aires: La Ley.

Gatti, Á. E. (2015) Derecho del Trabajo. Manual de las relaciones individuales. Buenos Aires: Ediciones B de F.

Jaime, R. C. y Brito Peret, J. I. (1996). Régimen Previsional. Sistema Integrado de Jubilaciones y Pensiones. Buenos Aires: Astrea.

López, J.; Centeno, N. y Fernández Madrid, J. C. (1987). Ley de Contrato de Trabajo Comentada. Buenos Aires: Ed. Contabilidad Moderna.

Ojeda, R. H. (2011). Ley de Contrato de Trabajo. Comentada y Concordada. (Coord.). Santa Fe: Rubinzal-Culzoni.

Organización Mundial de la Salud. Recuperado de https://www.who.int/ countries/arg/es/

Rigoni, S. (2003). Régimen Previsional de la Provincia de Buenos Aires. Buenos Aires: Scotti Editora.

\section{Legislación Nacional consultada}

Constitución de la República Argentina.

Ley No 18.037. Boletín Oficial de la República Argentina, Buenos Aires, 10/01/1969.

Ley No 20.744. Boletín Oficial de la República Argentina, Buenos Aires, 27/09/1974.

Ley No 23.451. Boletín Oficial de la República Argentina, Buenos Aires, 14/04/1987.

Ley No 23.592. Boletín Oficial de la República Argentina, Buenos Aires, 05/09/1988.

Ley No 24.013. Boletín Oficial de la República Argentina, Buenos Aires, 17/12/1991. 
Ley No 24.241. Boletín Oficial de la República Argentina, Buenos Aires, 18/10/1993. Ley No 24.397. Boletín Oficial de la República Argentina, Buenos Aires, 29/06/1994. Ley No 25.655. Boletín Oficial de la República Argentina, Buenos Aires, 16/10/2002. Ley No 27.426. Boletín Oficial de la República Argentina, Buenos Aires, 28/12/2017.

\section{Legislación Provincial consultada}

Decreto Ley No 9650/80. Boletín Oficial de la Provincia de Buenos Aires, 30/12/1980.

Ley No 10579. Boletín Oficial de la Provincia de Buenos Aires, 30/12/1987.

\section{Jurisprudencia de la Corte Suprema de Justicia de la Nación}

Fallos 289:430.

Fallos 331:72.

Fallos 330:5197.

Fallos 313:579.

Fallos 332:850.

Fallos 294:94.

CSJN, M 217. XXXV. "Melo Miguel Ángel c/Máxima AFJP s/ jubilación por invalidez ley 24241”, sent. 24/08/2000.

CSJN, Tomo 310, Volumen 1. "Lenta, Dominga s/ Jubilación”, sent. 12/03/1987.

Jurisprudencia de la Suprema Corte Justicia de la Provincia de Buenos Aires

Causa: "Barragán, Mario Argentino contra Taberna Hnos. Indemnización por despido", L 98.663, sent. del 05/06/2013. Recuperado de https://juba.scba.gov.ar/ Busquedas.aspx.

Causa: "Acosta, María Lilian P. c/ Provincia de Buenos Aires (Instituto de Previsión Social) s/ Demanda contencioso administrativa", B 65758, sent. del 31/10/2016. Recuperado de https://juba.scba.gov.ar/Busquedas.aspx.

Causa: "Milocco, Laura Amelia contra Provincia de Buenos Aires (Instituto de Previsión Social). Demanda contencioso administrativa", causa B. 63.845, 
sentencia del 25/11/2009. Recuperado de https://juba.scba.gov.ar/Busquedas. aspx.

Causa: "Cal Herbertz, María de los Dolores contra Provincia de Buenos Aires (Instituto de Previsión Social). Demanda contencioso administrativa”, causa B. 58.854, sent. del 16/08/2000. Recuperado de https://juba.scba.gov.ar/Busquedas. aspx.

Causa: "Diani, Rubén Ramón c/ Air Liquid de Argentina S.A. s/ Despido", RI 117.908, sent. del 03/09/2014. Recuperado de https://juba.scba.gov.ar/Busquedas.aspx.

Causa: "Cachero José Román c/ Televisión Federal S.A (Telefé S.A.) s/ indemnización por despido", L 112.734, sent. del 20/03/2013. Recuperado de https://juba. scba.gov.ar/Busquedas.aspx.

Causa: "Liptak Ghiloni, Enrique c/ Roberto L. Bottino SACIF s/ indemnización por antigüedad", L 87039, sent. del 05/05/2010. Recuperado de https://juba.scba. gov.ar/Busquedas.aspx.

\section{Jurisprudencia de la Cámara Federal de Apelaciones de la Seguridad Social}

Causa: “Ocampo Raúl c/ Siembra AFJP s/ Prestaciones varias", Sala I, sent. 18/10/2007.

Causa: "Zarza Claudia Elizabeth c/ ANSES s/ retiro por invalidez (art. 49 P. 4 LEY 24.241)", Sala II, sent. 30/09/2014.

\section{Jurisprudencia de la Cámara Nacional de Apelaciones del Trabajo}

Plenario No 321: "Couto de Capa, Irene Marta c/ Aryva S.A. s/ Ley 14.546", del 05/06/2009.

Fecha de recepción: 27-03-2019

Fecha de aceptación: 10-09-2019 
